\title{
Inoculum type response to different pHs on biohydrogen production from L-arabinose, a component of hemicellulosic biopolymers
}

\author{
A.A. Abreu, A.S. Danko, J.C. Costa, E.C. Ferreira, M.M. Alves* \\ IBB - Institute for Biotechnology and Bioengineering, Centre of Biological Engineering, University of Minho, Campus Gualtar, \\ 4710-057 Braga, Portugal
}

\section{A R T I C L E I N F O}

Article history:

Received 17 October 2008

Received in revised form

4 December 2008

Accepted 4 December 2008

Available online 25 January 2009

Keywords:

Biohydrogen

$\mathrm{pH}$

L-Arabinose

PCA

PLS

\begin{abstract}
A B S T R A C T
Biohydrogen production from arabinose was examined using four different anaerobic sludges with different pHs ranging from 4.5 to 8.0. Arabinose $\left(30 \mathrm{~g} \mathrm{l}^{-1}\right)$ was used as the substrate for all experiments. Individual cumulative hydrogen production data was used to estimate the three parameters of the modified Gompertz equation. Higher hydrogen production potentials were observed for higher $\mathrm{pH}$ values for all the sludges. G2 (acclimated granular sludge) showed the highest hydrogen production potential and percentage of arabinose consumption compared to the other sludges tested. Granular sludges (G1 and G2) showed different behaviour than the suspended sludges (S1 and S2). The differences were observed to be smaller lag phases, the percentage of acetate produced, the higher percentage of ethanol produced, and the amount of arabinose consumed. A high correlation $\left(R^{2}=0.973\right)$ was observed between the percentage of $n$-butyrate and the percentage of ethanol in G1 sludge, suggesting that ethanol/butyrate fermentation was the dominant fermentative pathway followed by this sludge. In $\mathrm{S} 1$, however, the percentage of $n$-butyrate was highly correlated with the percentage of acetate $\left(R^{2}=0.980\right)$. This study indicates that granular sludge can be used for larger $\mathrm{pH}$ ranges without reducing its capacity to consume arabinose and achieve higher hydrogen production potentials.

( 2008 International Association for Hydrogen Energy. Published by Elsevier Ltd. All rights
\end{abstract} reserved.

\section{Introduction}

Hydrogen is now considered one of the alternatives to fossil fuels. It is preferred to biogas or methane because hydrogen is not chemically bound to carbon and therefore, combustion does not contribute to green house gases or acid rain [1]. While there are numerous ways to produce $\mathrm{H}_{2}$ from renewable energy sources, currently the majority of $\mathrm{H}_{2}$ is produced from fossil fuels [2]. One alternative to sustainable $\mathrm{H}_{2}$ energy production from renewable energy sources is through microbiological fermentation or photosynthesis. Dark fermentation produces $\mathrm{H}_{2}$ at higher rates than photosynthesis and has the potential to combine organic waste management with simultaneous $\mathrm{H}_{2}$ production [3].

Biological hydrogen production is affected by several environmental factors such as $\mathrm{pH}$ [4,5]. Fermentative hydrogen production occurs during the acidification stage and $\mathrm{pH}$ is one of the important factors that affect this process. A change in system $\mathrm{pH}$ may result in decreased process efficiency. In general, the optimum initial $\mathrm{pH}$ for biohydrogen production is generally reported to be between 5.0 and 6.0 [6-8]. However, there have been conflicted reports about the

\footnotetext{
* Corresponding author. Tel.: +351 253604 400; fax: +351 253678986.

E-mail address: madalena.alves@deb.uminho.pt (M.M. Alves). 0360-3199/\$ - see front matter @ 2008 International Association for Hydrogen Energy. Published by Elsevier Ltd. All rights reserved. doi:10.1016/j.ijhydene.2008.12.020
} 
optimum $\mathrm{pH}$ value because the optimum $\mathrm{pH}$ in batch biohydrogen production was determined to be 9.0 with sucrose [9]. There have been many studies examining the effect of $\mathrm{pH}$ in fermentative hydrogen production from glucose and sucrose using mixed microflora [6,9-12]. Although the influence of $\mathrm{pH}$ on the fermentative biohydrogen production using arabinose, one of the most common pentoses and a component of various biopolymers such as hemicellulose, is not well known. Previous studies reported biohydrogen production from arabinose using mixed cultures but the effect of $\mathrm{pH}$ is not described $[13,14]$. The effect of $\mathrm{pH}$ on the biohydrogen production from arabinose was examined using a pure culture but the range of $\mathrm{pH}$ values tested was limited and the soluble microbial products were not identified [15]. Understanding the effect of $\mathrm{pH}$ is necessary to develop arabinose-based hydrogen fermentation applications, such as the use of agricultural wastes. The purpose of this study was to investigate the effect of initial $\mathrm{pH}$ on biohydrogen production from arabinose using mixed cultures in order to evaluate the feasibility of applying arabinose-based hydrogen fermentation in a continuous system.

\section{Materials and methods}

\subsection{Batch experiments}

\subsubsection{Seed sludges}

Four different biomasses were tested for hydrogen production as follows: S1 (disperse anaerobic digester sludge from municipal WWTP), S2 (disperse anaerobic digester sludge from municipal WWTP supplemented with fat), G1 (anaerobic granular sludge from industrial WWTP from brewery waste) and G2 from a hydrogen producing reactor fed glucose and L-arabinose (1/1) $5 \mathrm{~g} \mathrm{COD} \mathrm{l}^{-1}$ final concentration, during $120 \mathrm{~d}$ [16]. S1, S2 and G1 sludges were heat treated at $121{ }^{\circ} \mathrm{C}$ for $30 \mathrm{~min}$ to $2 \mathrm{~h}$ to inhibit methanogenic activity.

\subsubsection{Experimental procedures}

The experiments were conducted using $125 \mathrm{ml}$ serum bottles. L-Arabinose was used as the substrate at an initial concentration of $30 \mathrm{~g} \mathrm{COD} \mathrm{l}^{-1}$. Four series of batch experiments were conducted, one for each biomass.

Anaerobic buffer [17] (20 ml) was added to each vial containing $10 \mathrm{~g} \mathrm{VSSl}^{-1}$ of biomass and nutrients for bacterial growth (18 $\mathrm{ml} \mathrm{l}^{-1}$ of macronutrients $-\mathrm{MgSO}_{4} \cdot 7 \mathrm{H}_{2} \mathrm{O}: 30 \mathrm{~g} \mathrm{l}^{-1} ; \mathrm{KH}_{2} \mathrm{PO}_{4}$ : $28.3 \mathrm{~g} \mathrm{l}^{-1}$; $\mathrm{NH}_{4} \mathrm{Cl}: 170 \mathrm{~g} \mathrm{l}^{-1}$ and $1 \mathrm{ml} \mathrm{l}^{-1}$ of micronutrients $\mathrm{FeCl}_{2} \cdot 6 \mathrm{H}_{2} \mathrm{O}: 2 \mathrm{gl}^{-1} ; \mathrm{H}_{3} \mathrm{BO}_{3}: 0.05 \mathrm{gl}^{-1} ; \mathrm{ZnCl}_{2}: 0.05 \mathrm{gl}^{-1} ; \mathrm{CuCl}_{2} \cdot 2 \mathrm{H}_{2} \mathrm{O}$ : $0.038 \mathrm{gl}^{-1} ; \mathrm{MnCl}_{2} \cdot 4 \mathrm{H}_{2} \mathrm{O}: 0.5 \mathrm{gl}^{-1} ;\left(\mathrm{NH}_{4}\right)_{6} \mathrm{Mo}_{7} \mathrm{O}_{24} \cdot 4 \mathrm{H}_{2} \mathrm{O}: 0.05 \mathrm{gl}^{-1}$; $\mathrm{AlCl}_{3} \cdot 6 \mathrm{H}_{2} \mathrm{O}: 0.09 \mathrm{gl}^{-1} ; \mathrm{CoCl}_{2} \cdot 6 \mathrm{H}_{2} \mathrm{O}: 2 \mathrm{gl}^{-1} ; \mathrm{NiCl}_{2} \cdot 6 \mathrm{H}_{2} \mathrm{O}: 0.092 \mathrm{gl}^{-1}$; $\mathrm{Na}_{2} \mathrm{SeO}_{3} \cdot 5 \mathrm{H}_{2} \mathrm{O}: 0.164 \mathrm{gl}^{-1}$; EDTA: $1 \mathrm{gl}^{-1}$; Resazurin: $0.2 \mathrm{gl}^{-1} ; \mathrm{HCl}$ $37 \%[18])$.

Eight different pHs (4.5; 5.0; 5.5; 6.0; 6.5; 7.0; 7.5; and 8.0) were tested in triplicate. The initial $\mathrm{pH}$ of individual bottles was adjusted adding $\mathrm{HCl}$ or $\mathrm{NaOH}$ and flushing with $100 \% \mathrm{~N}_{2}$, $20 \% \mathrm{CO}_{2} / 80 \% \mathrm{~N}_{2}$ or $100 \% \mathrm{CO}_{2}$. The bottles were sealed, placed on a rotary shaker (150 rpm), and incubated at $37{ }^{\circ} \mathrm{C}$. Hydrogen, VFA, and ethanol concentrations for the control inoculum ( $0 \mathrm{~g} \mathrm{l}^{-1}$ of substrate) were subtracted from values obtained for each $\mathrm{pH}$.
Gas pressure was released using a glass syringe (20 and $50 \mathrm{ml}$ capacity) by the Owen method [19]. The amount of gas present in the headspace of each bottle was determined before and after releasing gas pressure.

\subsubsection{Monitoring and analysis}

Soluble COD was determined according to Standard Methods [20]. Volatile fatty acids (VFAs) (formate, acetate, propionate, iso-butyrate, n-butyrate, valerate), ethanol, and L-arabinose were determined by high performance liquid chromatography (Jasco, Japan) with a Chrompack column $\left(6.5 \times 30 \mathrm{~mm}^{2}\right)$. Sulfuric acid $(0.01 \mathrm{~N})$ was used as mobile phase at a flow rate of $0.7 \mathrm{ml} \mathrm{min}{ }^{-1}$. The column temperature was set at $60{ }^{\circ} \mathrm{C}$. Detection of soluble products was made sequentially with a UV detector at $210 \mathrm{~nm}$ (VFAs) and a Refraction Index (RI) detector (ethanol and L-arabinose), respectively.

Hydrogen in the headspace of bottles was determined by gas chromatography (GC) using a pressure-lock syringe $(0.2 \mathrm{ml}$ injection volume) and a Hayesep Q column (80/100 mesh) and thermal conductivity detector (Varian 3300 Gas Chromato-

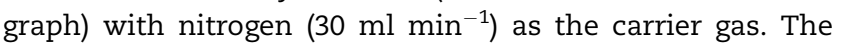
injector, detector, and column temperatures were 120, 170, and $35{ }^{\circ} \mathrm{C}$, respectively. Methane was analysed by GC using a Porapack Q (100-180 mesh) column with $\mathrm{N}_{2}$ as the carrier gas

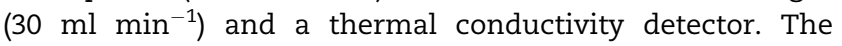
temperatures of the detector, injector, and oven were 110, 110 and $35^{\circ} \mathrm{C}$, respectively.

The modified Gompertz equation was used to describe the progress of cumulative hydrogen production obtained from the batch experiments [21,22]. Using the cumulative hydrogen production data, corrected to STP conditions $\left(0^{\circ} \mathrm{C}\right.$ and $\left.1 \mathrm{~atm}\right)$, the maximum hydrogen production rates were estimated from the fit of the modified Gompertz equation (equation (1)).

$H(t)=P \exp \left\{-\exp \left[\frac{R_{m} e}{P}(\lambda-t)+1\right]\right\}$

where $H(t)$ is cumulative hydrogen production (ml), $P$ hydrogen production potential $(\mathrm{ml}), R_{\mathrm{m}}$ maximum hydrogen production rate $\left(\mathrm{ml} \mathrm{h}^{-1}\right), e=2.71828 \ldots, \lambda$ lag-phase time (h), and $t$ time $(h) . R^{2}$ values and the standard errors of each variable were calculated.

\subsubsection{Principal Components Analysis (PCA)}

Principal components (PC) analysis was used in order to find and interpret hidden complex relationships between features in a data set. PCA is a technique for summarizing the information contained in variables by a few weighted components as a mean of reducing the number of variables needed in an analysis. Correlating features were converted to the so-called factors which are themselves noncorrelated [23]. PCA modelling shows the correlation structure of data matrix $X$, approximating it by a first term $1 * \overline{X^{\prime}}$ representing the variables' average plus a matrix product of lower dimension $\left(\mathrm{TP}^{\prime}\right)$, called the principal components, plus a matrix of residuals $(E)$.

$\mathrm{X}=1 * \overline{\mathrm{X}^{\prime}}+\mathrm{TP}^{\prime}+\mathrm{E}$

SIMCA-P (Umetrics AB) software package was used to perform the PCA; it iteratively computes one principal component at a time, comprising a score vector $t$ and a loading vector $p$. The score vectors contain information on how the samples relate 
to each other (matrix $T$ ). Otherwise, the loading vectors define the reduced dimension space and contain information on how the variables relate to each other (matrix P). Usually, a few PC (2 or 3) can express most of the variability in the database when a high degree of correlation among data exists.

The criterion used to determine the model dimensionality (number of significant components) is cross-validation (CV). Part of data is kept out of the model development, and then is predicted by the model and compared with the actual values. The prediction error sum of squares (PRESS) is the squared differences between observed and predicted values for the data kept out of the model fitting. This procedure is repeated several times until the data elements have been kept out once and only once. Therefore, the final PRESS has contributions from all data. For every dimension, SIMCA computes the overall PRESS/SS, where SS is the residual sum of squares of the previous dimension. A component is considered significant if PRESS/SS is statistically smaller than 1.0.

\subsubsection{Partial Least Squares regression (PLS)}

PLS is an iterative algorithm that extracts linear combinations of the essential features of the original data $X$ while modelling the $Y$ data dependence on the data set, being well suited for multivariate calibration. The most important advantage of this method reports to the non-problematic handling of multicollinearities relying on an iterative algorithm, which makes possible the treatment of data with more features than objects [23].

In this method, the latent variables $u$ (matrix $U$ ) are used for modelling the objects separately in the matrix of $Y$ dependent data, whereas, the $t$ variables (matrix $T$ ) are used for modelling the objects separately in the $X$ matrix of independent data. The latent variables $U$ and $T$ are the basis of the regression model and are determined by:

$U=A T+E$

(PLS components matrix A and error matrix E) in an iterative process with the centred matrices of $X$ and $Y$ as starting points [23].

SIMCA-P (Umetrics AB) software package was used to perform PLS analysis from the data set. This software iteratively computes one PLS at a time, that is, one vector for each of $X$-scores $(t)$, Y-scores $(u)$, weights $(w)$ expressing the correlation between $X$ and $U$, weights (c) expressing the correlation between $Y$ and $T$ and loadings $(p)$. The PLS components are calculated in descending order of importance. For the response variables $(m)$ in $Y$, the multiple correlation coefficient $\left(R^{2} Y_{\text {cum }}\right)$ or goodness of fit is given by:

$R^{2} Y_{\text {cum }}=\sum R^{2} Y_{a}$

where $R^{2} Y_{a}$ is the sum of squares of the entire $Y$ 's explained by each extracted component (a).

\section{Results and discussion}

\subsection{Effect of $\mathrm{pH}$ on hydrogen production potentials, rates and lag times}

Biohydrogen production from arabinose was examined using initial $\mathrm{pH}$ values ranging from 4.5 to 8.0 for four different anaerobic sludges. The initial substrate concentration was $30 \mathrm{gl}^{-1} \mathrm{COD}$ for all experiments with $0 \mathrm{gl}^{-1}$ serving as control. Individual cumulative hydrogen production data was used to estimate the three parameters of the modified Gompertz equation (maximum hydrogen production rate, hydrogen production potential, and duration of the lag phase). Hydrogen production occurred for all four sludges but there were differences in the yields, lag times, and rates (Table 1). Methane production was not detected in any of the batch cultures indicating that methanogenic activity was inhibited. $\mathrm{pH}$ was measured at the end of each batch experiment and the values were determined to be approximately 5.0 for all the biomasses tested (data not shown).

G1 was determined to have the highest hydrogen production potential $(61.6 \pm 0.1 \mathrm{ml})$ at $\mathrm{pH}$ of 6.5 while the highest hydrogen production rate $\left(2.3 \pm 0.2 \mathrm{ml} \mathrm{h}^{-1}\right)$ was obtained at a $\mathrm{pH}$ of 7.0 . Also, the shortest lag time $(10.6 \pm 2.4 \mathrm{~h})$ was detected at a pH of 8.0 (Table 1). G2 was determined to have the highest hydrogen production potential $(137.2 \pm 9.6 \mathrm{ml}$ at $\mathrm{pH}$ 7.5) when compared with the other sludges tested. G2 showed the highest hydrogen production rate $\left(2.9 \pm 0.2 \mathrm{ml} \mathrm{h}^{-1}\right)$ at $\mathrm{pH} 7.5$ and lower lag phase $(11 \pm 1.8 \mathrm{~h}$ at $\mathrm{pH}$ 7.0). Concerning the $\mathrm{S} 1$ sludge, the highest hydrogen production potential $(51.1 \pm 1.3 \mathrm{ml})$ and rate $\left(2.8 \pm 0.4 \mathrm{ml} \mathrm{h}^{-1}\right)$ occurred at a $\mathrm{pH}$ of 7.0. The shortest lag time was obtained with $\mathrm{pH} 6.0$ (Table 1). For S2 sludge, the highest hydrogen production potential was observed with $\mathrm{pH} 8.0(58.1 \pm 1.8 \mathrm{ml})$ and the maximum rate $\left(4.8 \pm 1.4 \mathrm{ml} \mathrm{h}^{-1}\right)$ was obtained with $\mathrm{pH}$ 7.5 (Table 1).

Higher hydrogen production potentials corresponding to higher $\mathrm{pH}$ values have been observed in other studies [9]. When comparing all four sludges, G2 obtained the highest hydrogen production potential $(137.2 \mathrm{ml})$ and $\mathrm{S} 2$ obtained the largest hydrogen production rate $\left(4.8 \mathrm{ml} \mathrm{h}^{-1}\right)$ at a $\mathrm{pH}$ of 7.5 , while G1 obtained the shortest lag time (10.6 h) at a pH of 8.0. Comparing these results with previous studies using mixed cultures [13] a higher hydrogen production potential and hydrogen production rates as well as a significant reduction in lag phases were obtained. Jianzheng et al. [13] reported a cumulative hydrogen yield of $34 \mathrm{ml}$, hydrogen production rate of $0.8 \mathrm{ml} \mathrm{h}^{-1}$ and a lag phase of $68 \mathrm{~h}$ using a $\mathrm{pH}$ of 6 .

\subsection{Effect of $p H$ on arabinose consumption and hydrogen yields}

Hydrogen yields were calculated for all batch reactors based on the amount of arabinose consumed and the amount of hydrogen produced. The results are shown in Table 1 . The highest hydrogen yield was obtained with S2 $(2.5 \mathrm{~mol}$

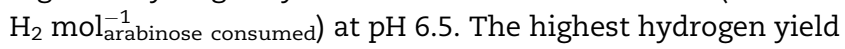

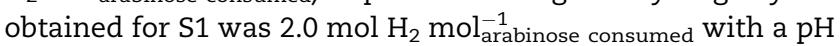
of 7.0 and 8.0 and the highest hydrogen yield obtained for $\mathrm{G} 2$

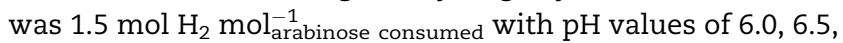
7.5 and 8.0. G1 had the smallest hydrogen yield $(1.3 \mathrm{~mol}$ $\mathrm{H}_{2}$ mol arabinose consumed; $\mathrm{pH}=6.5$ ) when compared with the other biomasses. However, the minimum amount of arabinose consumed for $\mathrm{G} 1$ was at least $41 \%$ for all $\mathrm{pH}$ values. For S2, the highest percentage of arabinose consumed was $39.7 \%$ at $\mathrm{pH}$ 8.0. The highest percentage for $\mathrm{S} 1$ was only $33.3 \%$ at a $\mathrm{pH}$ 
Table 1 - Modified Gompertz equation parameter values, percentage of arabinose consumed, COD balance, hydrogen yields for the different pH's tested.

\begin{tabular}{|c|c|c|c|c|c|c|c|}
\hline $\mathrm{pH}$ & $P(\mathrm{ml})$ & $R_{\mathrm{m}}\left(\mathrm{ml} \mathrm{h}^{-1}\right)$ & Lambda $(\lambda)$ & $R^{2}$ & $\begin{array}{c}\text { Arabinose } \\
\text { consumed (\%) }\end{array}$ & COD balance (\%) & $\begin{array}{l}\text { Yield (mol } \mathrm{H}_{2} \mathrm{~mol}^{-1} \\
\text { arabinose consumed) }\end{array}$ \\
\hline \multicolumn{8}{|c|}{ G1 sludge } \\
\hline 4.5 & $27.7 \pm 0.6$ & $0.7 \pm 0.1$ & $21.9 \pm 2.3$ & 0.99 & 42.1 & 105.3 & $0.8 \pm 0.1$ \\
\hline 5.0 & $26.2 \pm 0.5$ & $0.9 \pm 0.1$ & $17.1 \pm 1.2$ & 0.99 & 41.1 & 107.4 & $0.8 \pm 0.2$ \\
\hline 5.5 & $32.2 \pm 0.7$ & $0.9 \pm 0.1$ & $15.9 \pm 1.9$ & 0.99 & 44.8 & 115.3 & $0.8 \pm 0.1$ \\
\hline 6.0 & $54.3 \pm 1.5$ & $1.2 \pm 0.1$ & $17.2 \pm 1.9$ & 0.99 & 50.5 & 99.6 & 1.2 \\
\hline 6.5 & $61.6 \pm 0.1$ & $2.1 \pm 0.1$ & $15.2 \pm 0.9$ & 1.00 & 53.8 & 99.5 & 1.3 \\
\hline 7.0 & $56.4 \pm 1.2$ & $2.3 \pm 0.2$ & $12.3 \pm 1.2$ & 0.99 & 52.0 & 100.6 & $1.2 \pm 0.1$ \\
\hline 7.5 & $51.2 \pm 1.1$ & $2.0 \pm 0.2$ & $11.6 \pm 1.4$ & 0.99 & 52.6 & 100.3 & $1.1 \pm 0.1$ \\
\hline 8.0 & $41.3 \pm 1.7$ & $1.8 \pm 0.4$ & $10.6 \pm 2.4$ & 0.96 & 54.6 & 93.3 & $0.9 \pm 0.1$ \\
\hline \multicolumn{8}{|c|}{ G2 sludge } \\
\hline 4.5 & 0.0 & 0.0 & 0.0 & na & 19.9 & 90.2 & 0.0 \\
\hline 5.0 & $11.8 \pm 0.1$ & $0.9 \pm 0.1$ & $50.2 \pm 0.7$ & 0.99 & 24.8 & 87.0 & $0.5 \pm 0.18$ \\
\hline 5.5 & $47.2 \pm 0.4$ & $2.1 \pm 0.1$ & $19.3 \pm 0.6$ & 0.99 & 50.0 & 93.7 & $1.1 \pm 0.1$ \\
\hline 6.0 & $93.0 \pm 0.4$ & $2.6 \pm 0.04$ & $18.8 \pm 0.3$ & 0.99 & 72.3 & 109.8 & $1.5 \pm 0.2$ \\
\hline 6.5 & $111.8 \pm 1.4$ & $2.9 \pm 0.16$ & $14.5 \pm 1.1$ & 0.99 & 80.7 & 116.4 & $1.5 \pm 0.03$ \\
\hline 7.0 & $97.4 \pm 1.9$ & $2.3 \pm 0.2$ & $11.0 \pm 1.8$ & 0.99 & 75.7 & 117.0 & $1.4 \pm 0.21$ \\
\hline 7.5 & $137.2 \pm 9.6$ & $1.7 \pm 0.2$ & $13.7 \pm 4.7$ & 0.97 & 92.4 & 115.8 & $1.5 \pm 0.05$ \\
\hline 8.0 & $136.7 \pm 6.4$ & $1.9 \pm 0.2$ & $15.4 \pm 3.3$ & 0.98 & 97.6 & 114.5 & $1.5 \pm 0.05$ \\
\hline \multicolumn{8}{|c|}{ S1 sludge } \\
\hline 4.5 & $0.4 \pm 0.04$ & $1.0 \pm 0.2$ & $80.0 \pm 0.2$ & 0.89 & 8.8 & 104.8 & 0.1 \\
\hline 5.0 & $11.3 \pm 0.1$ & $0.8 \pm 0.04$ & $56.1 \pm 0.4$ & 1.00 & 13.2 & 113.0 & $0.7 \pm 0.1$ \\
\hline 5.5 & $19.3 \pm 0.8$ & $1.0 \pm 0.2$ & $25.9 \pm 1.7$ & 0.98 & 11.3 & 114.0 & $2.0 \pm 0.6$ \\
\hline 6.0 & $24.4 \pm 0.5$ & $1.8 \pm 0.2$ & $18.7 \pm 0.9$ & 0.99 & 22.2 & 119.8 & $1.3 \pm 0.3$ \\
\hline 6.5 & $38.0 \pm 1.1$ & $1.9 \pm 0.3$ & $29.5 \pm 1.7$ & 0.99 & 28.8 & 107.7 & $1.6 \pm 0.1$ \\
\hline 7.0 & $51.1 \pm 1.3$ & $2.8 \pm 0.4$ & $24.1 \pm 1.3$ & 0.99 & 29.6 & 108.9 & $2.0 \pm 0.1$ \\
\hline 7.5 & $47.4 \pm 1.8$ & $2.5 \pm 0.5$ & $22.6 \pm 2.0$ & 0.98 & 33.3 & 106.1 & 1.7 \\
\hline 8.0 & $46.9 \pm 1.2$ & $2.2 \pm 0.3$ & $24.0 \pm 1.4$ & 0.99 & 28.5 & 106.5 & $2.0 \pm 0.3$ \\
\hline \multicolumn{8}{|c|}{ S2 sludge } \\
\hline 4.5 & $23.2 \pm 1.3$ & $0.5 \pm 0.1$ & $26.0 \pm 2.9$ & 0.98 & 19.9 & 95.2 & $1.3 \pm 0.1$ \\
\hline 5.0 & $35.7 \pm 2.1$ & $1.2 \pm 0.2$ & $37.5 \pm 2.8$ & 0.98 & 24.9 & 95.1 & $1.5 \pm 0.1$ \\
\hline 5.5 & $34.5 \pm 1.5$ & $1.4 \pm 0.2$ & $31.9 \pm 2.1$ & 0.99 & 23.0 & 101.9 & $1.7 \pm 0.2$ \\
\hline 6.0 & $49.4 \pm 0.5$ & $1.9 \pm 0.1$ & $28.3 \pm 0.6$ & 1.00 & 22.1 & 101.3 & 2.5 \\
\hline 6.5 & $54.4 \pm 0.4$ & $3.3 \pm 0.1$ & $27.9 \pm 0.4$ & 1.00 & 34.5 & 102.9 & $1.8 \pm 0.2$ \\
\hline 7.0 & $47.1 \pm 0.5$ & $3.0 \pm 0.4$ & $19.4 \pm 1.5$ & 1.00 & 32.4 & 99.1 & $1.7 \pm 0.1$ \\
\hline 7.5 & $56.3 \pm 1.5$ & $4.8 \pm 1.4$ & $32.8 \pm 2.4$ & 1.00 & 39.6 & 108.9 & $1.2 \pm 0.7$ \\
\hline 8.0 & $58.1 \pm 1.8$ & $2.4 \pm 0.3$ & $28.2 \pm 1.6$ & 1.00 & 39.7 & 103.0 & 1.7 \\
\hline
\end{tabular}

of 7.5. G2 was observed to have the highest percentage of arabinose consumption (97\%) at a $\mathrm{pH}$ of 8.0 .

The yields obtained in this study are less than the theoretical value ( $3.3 \mathrm{~mol} \mathrm{H}_{2} \mathrm{~mol}_{\text {arabinose}}^{-1}$ ). Although, compared to the values obtained in a previous study that used xylose (pentose) (20 $\left.\mathrm{g} \mathrm{COD}^{-1}\right)$ as a substrate [24] the maximum yields obtained in this study are slightly higher. The highest yield obtained in the previous study using xylose $\left(2.25 \mathrm{~mol} \mathrm{H}_{2} \mathrm{~mol}_{\text {xylose }}^{-1}\right)$ was observed at a pH of 6.5, while in the present study we were able

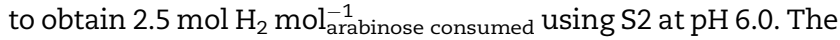
yields obtained in the present study were significantly higher than those obtained in a previous study that also used arabinose as the substrate $\left(10 \mathrm{~g} \mathrm{l}^{-1}\right)$ and mixed culture for hydrogen production ( $9.7 \mathrm{ml} \mathrm{H}_{2}$ garabinose consumed corresponds to $0.05 \mathrm{~mol}$ $\mathrm{H}_{2}$ mol arabinose consumed) [13]. The yields and amounts for hydrogen production were also different for this study when compared against the pure culture Clostridium (strain No. 2) fed with arabinose $\left(10 \mathrm{gl}^{-1}\right)$ [15]. The maximum yield for the strain

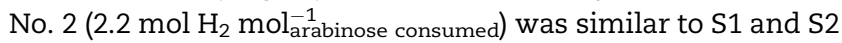
but was higher than the yields obtained with G1 and G2. The maximum amount of hydrogen production from Clostridium (strain No. 2) with controlled pH was $3600 \mathrm{ml} \mathrm{H}_{2} \mathrm{l}^{-1}$ culture and with uncontrolled $\mathrm{pH}$ was $2000 \mathrm{ml} \mathrm{H}_{2} \mathrm{l}^{-1}$ culture [15]. These values are similar to the maximum amounts of hydrogen production from S1 (2550 $\mathrm{ml} \mathrm{H}_{2} \mathrm{l}^{-1}$ culture), S2 (2900 $\mathrm{ml} \mathrm{H}_{2} \mathrm{l}^{-1}$ culture), and G1 (3100 ml H $\mathrm{l}^{-1}$ culture). However, G2 produced almost twice as much hydrogen $\left(6850 \mathrm{ml} \mathrm{H}_{2} \mathrm{l}^{-1}\right.$ culture) as strain No. 2.

\subsection{Effect of $p H$ on VFAs and ethanol production}

Soluble microbial products (SMPs) released during fermentation are often used to evaluate the efficiency of hydrogen production. The percentage of each VFA and ethanol at the end of each batch test for each pH tested is shown in Table 2 .

For G1 sludge, the SMP production achieved a maximum concentration of $19144 \mathrm{mg} \mathrm{COD} \mathrm{^{-1 }}$ at pH 5.5 (Table 2). All other $\mathrm{pH}$ values produced approximately $15000 \mathrm{mg}$ COD $\mathrm{l}^{-1}$. The total amount of SMP produced was higher when compared against the values obtained with S1 and S2. G2 
Table 2 - Total COD from VFAs and ethanol and percentage of each soluble microbial product (SMP) at the end of each batch test, for the different pHs.

\begin{tabular}{|c|c|c|c|c|c|c|c|c|}
\hline \multirow[t]{2}{*}{$\mathrm{pH}$} & \multirow{2}{*}{$\begin{array}{l}\text { VFAs + ethanol } \\
\left(\mathrm{mg} \mathrm{COD} \mathrm{l}^{-1}\right)\end{array}$} & \multicolumn{7}{|c|}{ Percentage (\%) } \\
\hline & & Formate & Acetate & Propionate & $\begin{array}{c}\text { i- } \\
\text { Butyrate }\end{array}$ & $\begin{array}{c}n- \\
\text { Butyrate }\end{array}$ & Valerate & Ethanol \\
\hline \multicolumn{9}{|c|}{ G1 sludge } \\
\hline 4.5 & 15257 & 0.0 & 3.4 & 0.0 & 0.0 & 13.8 & 0.0 & 82.8 \\
\hline 5.0 & 15710 & 0.0 & 3.8 & 0.0 & 0.0 & 14.4 & 0.0 & 81.8 \\
\hline 5.5 & 19144 & 0.1 & 8.4 & 0.0 & 0.0 & 28.6 & 0.0 & 62.9 \\
\hline 6.0 & 15050 & 0.1 & 4.7 & 0.0 & 0.0 & 23.4 & 0.0 & 71.8 \\
\hline 6.5 & 15765 & 0.3 & 6.1 & 0.0 & 0.0 & 29.6 & 0.0 & 63.9 \\
\hline 7.0 & 15734 & 0.8 & 4.9 & 0.0 & 0.0 & 27.7 & 0.0 & 66.5 \\
\hline 7.5 & 15945 & 0.6 & 6.2 & 0.0 & 0.0 & 28.4 & 0.0 & 64.8 \\
\hline 8.0 & 14643 & 0.6 & 3.7 & 0.0 & 0.0 & 34.4 & 0.0 & 61.2 \\
\hline \multicolumn{9}{|c|}{ G2 sludge } \\
\hline 4.5 & 574 & 0.0 & 0.0 & 0.0 & 0.0 & 17.8 & 0.0 & 82.2 \\
\hline 5.0 & 2862 & 0.0 & 10.5 & 3.1 & 0.0 & 22.0 & 0.0 & 64.5 \\
\hline 5.5 & 12278 & 0.0 & 9.9 & 3.8 & 0.0 & 30.4 & 0.0 & 56.0 \\
\hline 6.0 & 22931 & 0.0 & 10.1 & 1.4 & 0.0 & 31.2 & 0.0 & 57.3 \\
\hline 6.5 & 27274 & 0.0 & 9.9 & 1.2 & 0.0 & 31.2 & 0.0 & 57.7 \\
\hline 7.0 & 26276 & 0.0 & 8.2 & 1.5 & 0.0 & 32.9 & 0.0 & 57.4 \\
\hline 7.5 & 29400 & 0.0 & 8.2 & 0.9 & 0.0 & 31.1 & 0.0 & 59.8 \\
\hline 8.0 & 29717 & 0.0 & 8.3 & 0.7 & 0.0 & 29.8 & 0.0 & 61.2 \\
\hline \multicolumn{9}{|c|}{ S1 sludge } \\
\hline 4.5 & 993 & 7.9 & 64.1 & 8.3 & 4.3 & 6.4 & 0.0 & 0.0 \\
\hline 5.0 & 3976 & 1.6 & 24.1 & 3.7 & 0.9 & 48.8 & 0.0 & 19.7 \\
\hline 5.5 & 5547 & 1.1 & 20.9 & 1.8 & 0.0 & 60.8 & 0.0 & 15.4 \\
\hline 6.0 & 8119 & 1.0 & 17.6 & 1.6 & 0.6 & 64.8 & 0.0 & 15.7 \\
\hline 6.5 & 10224 & 1.7 & 23.3 & 0.0 & 0.4 & 57.0 & 0.2 & 16.2 \\
\hline 7.0 & 10410 & 0.9 & 19.7 & 0.0 & 0.0 & 62.3 & 0.2 & 16.2 \\
\hline 7.5 & 10779 & 1.1 & 19.7 & 0.0 & 0.0 & 61.5 & 0.2 & 17.3 \\
\hline 8.0 & 10340 & 1.2 & 17.9 & 0.0 & 0.0 & 62.2 & 0.4 & 17.1 \\
\hline \multicolumn{9}{|c|}{ S2 sludge } \\
\hline 4.5 & 4001 & 0.2 & 20.5 & 0.0 & 0.0 & 71.0 & 0.0 & 8.3 \\
\hline 5.0 & 5168 & 0.2 & 23.4 & 0.0 & 0.0 & 70.5 & 0.0 & 5.8 \\
\hline 5.5 & 5942 & 0.4 & 24.4 & 0.0 & 0.0 & 74.6 & 0.0 & 0.6 \\
\hline 6.0 & 5433 & 0.9 & 33.5 & 0.0 & 0.0 & 61.0 & 0.0 & 4.3 \\
\hline 6.5 & 9974 & 1.4 & 25.4 & 0.0 & 0.0 & 72.3 & 0.0 & 0.7 \\
\hline 7.0 & 8271 & 0.9 & 23.1 & 0.0 & 0.0 & 74.8 & 0.0 & 0.4 \\
\hline 7.5 & 11097 & 1.8 & 24.1 & 1.5 & 0.3 & 54.9 & 0.0 & 16.9 \\
\hline 8.0 & 11465 & 0.7 & 22.2 & 0.0 & 0.3 & 60.0 & 0.0 & 16.5 \\
\hline
\end{tabular}

obtained the highest SMP production compared to the other sludges (29 $717 \mathrm{mg} \mathrm{COD} \mathrm{l}^{-1}$ at $\mathrm{pH}$ 8.0). In addition, SMP was higher than $22931 \mathrm{mg} \mathrm{COD}^{-1}$ when $\mathrm{pH}$ values were higher than 5.5. The highest percentage of ethanol for all $\mathrm{pH}$ values was observed for G1 and G2 (Table 2). n-Butyrate was the second most abundant SMP for all $\mathrm{pH}$ values. Acetate was produced but corresponded to less than $6 \%$. The presence of large amounts of ethanol and small amounts of acetate may be one of the reasons for the smaller hydrogen yields obtained with G1 and G2 even though higher percentages of arabinose consumption were observed. This suggests that the system was following an ethanol type fermentation $[25,26]$.

Regarding the S1 sludge, the SMP production achieved

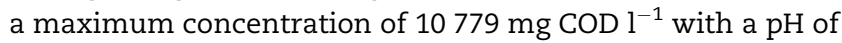
7.5 (Table 2). The most prominent SMP present for $\mathrm{pH}$ values greater than 4.5 was $n$-butyrate, corresponding to values between 50 and $65 \%$ of the SMP produced, followed by acetate (approximately 20\%) and ethanol (approximately 16\%) (Table 2). This suggests that the hydrogen is being produced via butyrate-acetate fermentation $[27,28]$. Acetate had the highest percentage of SMP production (approximately 70\%) at a $\mathrm{pH}$ of 4.5. However, the amount of arabinose consumed was very low (8.8\%).

S2 produced similar amounts of SMP to S1 although the distribution was slightly different. The highest amount of SMP (11 $465 \mathrm{mg} \mathrm{COD} \mathrm{l}^{-1}$ ) was observed at a $\mathrm{pH}$ of 8.0 (Table 2). The most prominent SMP present was $n$-butyrate, corresponding to approximately $70 \%$ of the total SMP produced at $\mathrm{pH}$ values of $4.5,5.0,5.5,6.5$ and 7.0, approximately $60 \%$ with $\mathrm{pH}$ values of 6.0 and 8.0 , and $55 \%$ with a pH of 7.5 (Table 2). Acetate was the second most abundant VFA for all $\mathrm{pH}$ values (approximately $20 \%$ ), except at pH 6.0 (approximately $34 \%$ ). This pH value (6.0) corresponded to the highest hydrogen yield $\left(2.5 \mathrm{~mol} \mathrm{H}_{2} \mathrm{~mol}^{-1}\right.$ arabinose consumed) and the highest percentage of acetate in all experiments, after $\mathrm{pH} 4.5$ from S1 sludge. Ethanol was present in all samples corresponding to less than $10 \%$ of the SMP for all $\mathrm{pH}$ values except for 7.5 and 8.0. This suggests that the hydrogen is being produced via butyrate-acetate fermentation 

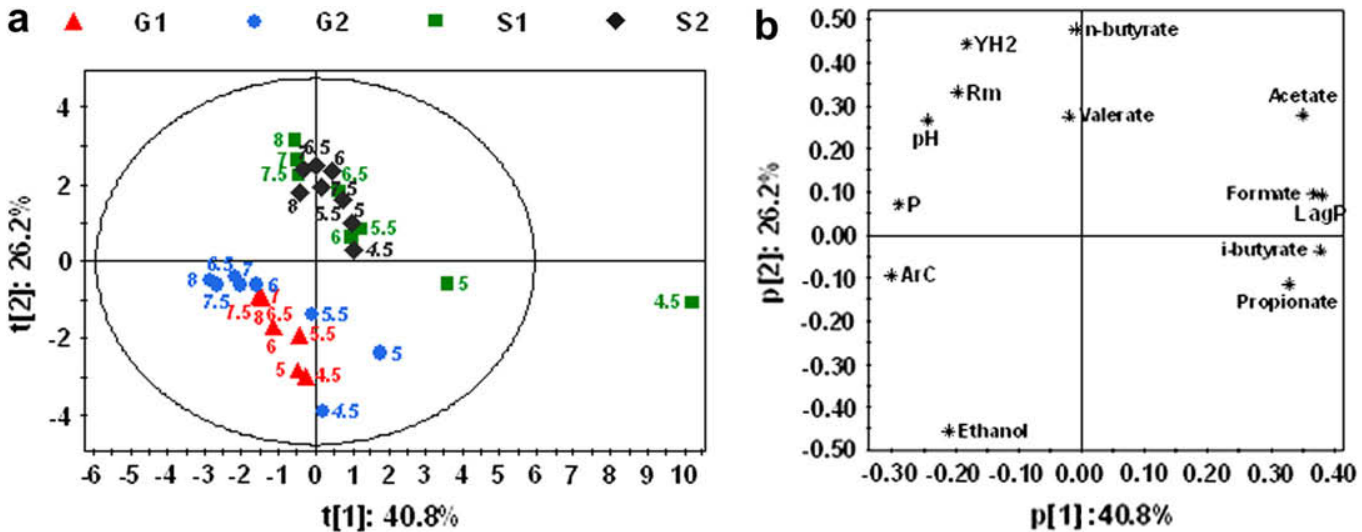

Fig. 1 - Score map (a) and loading map (b) obtained with Principal Components Analysis for all assays.

$[27,28]$. For all batch tests the COD balance indicated that the major metabolic products were identified (Table 1).

\subsection{Principal Components Analysis (PCA)}

Principal Components Analysis (PCA) was performed to visualize the main differences between the 4 biomasses tested. The data set consisted of 13 variables and 32 samples. All variables were autoscaled to unit variance, avoiding that some variables would be more important than others because of scale effects. The 3 first Principal Components (PC) contained
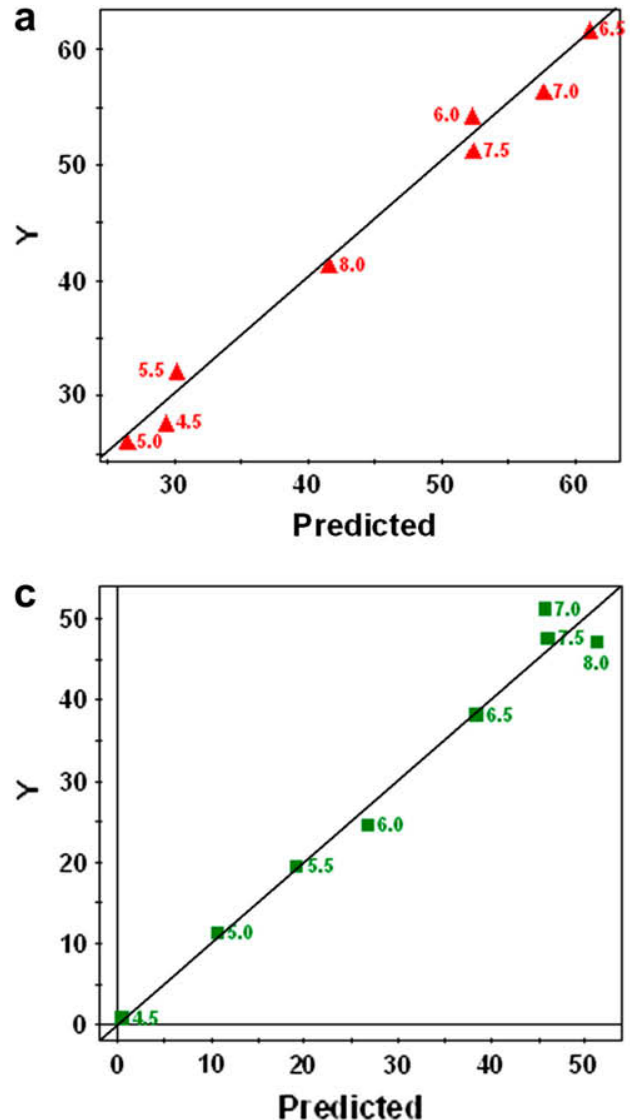

$82.4 \%$ of the total variability present in the data set. The use of more components did not significantly improve the robustness of the model. The plane t[1] us. $t$ [2] (Fig. 1a) shows that the granular sludges (G1 and G2) presented different behaviour than the suspended biomasses (S1 and S2). The score $\left(t_{i}\right)$ of an observation (i) on a principal component $P C_{j}\left(t_{i} P C_{j}\right)$ is the weighted sum of the original variables $\left(x_{i}\right)$. The weights $\left(p_{i}\right)$ are called the loadings of the variables on that $P C_{j}$. The loading of a variable is related to its variation [29].

$t_{i}\left(P C_{j}\right)=\sum\left[p_{i}\left(P C_{j}\right) * x_{i}\right]$
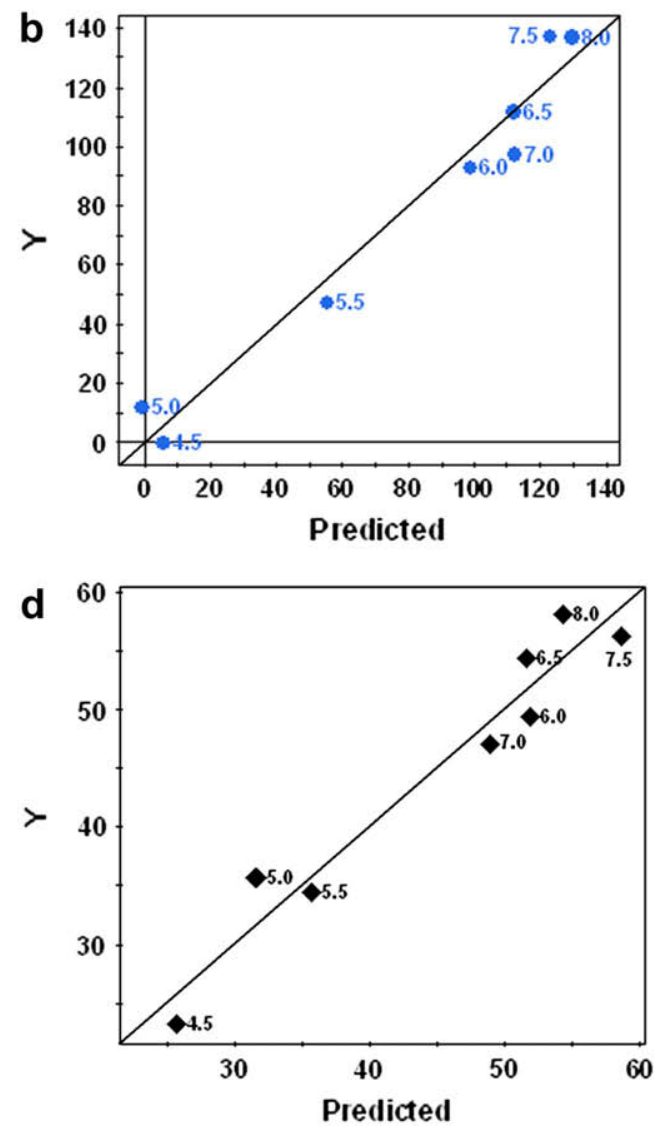

Fig. 2 - Hydrogen production potential (P), observed and predicted, with two latent variables for: (a) G1; (b) G2; (c) S1; and (d) S2. 

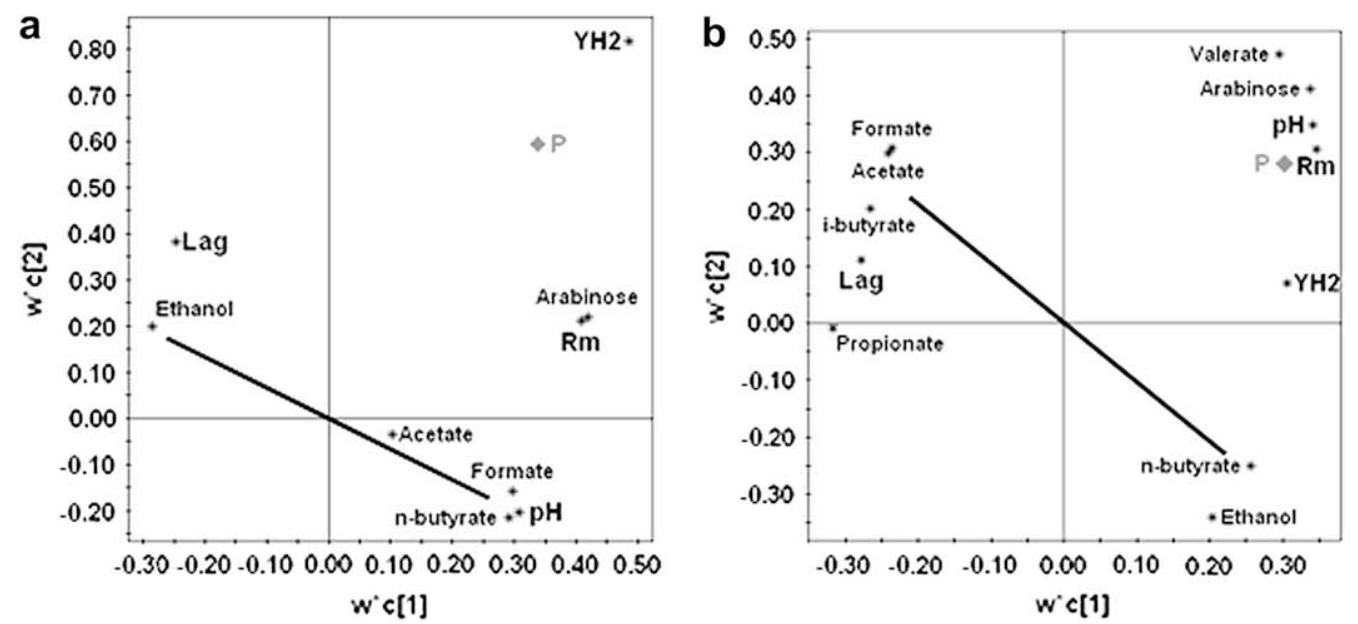

Fig. 3 - Loading maps for G (a), S1 (b), with $P$ as $Y$ variable.

Therefore, analyzing Fig. 1b ( $p[1]$ us. $p[2])$ we verify that the differences of granular sludges compared to suspended sludges are explained by smaller concentrations of VFAs, hydrogen yield $\left(\mathrm{Y}_{\mathrm{H}_{2}}\right)$ and percentages of acetate and n-butyrate, and also by higher \% of ethanol and arabinose consumed.

The sample corresponding to a $\mathrm{pH}$ of 4.5 from $\mathrm{S} 1$ (see Fig. 1a) is an outlier of the model because it shows higher percentages of formate, propionate, i-butyrate, and acetate, and smaller percentages of ethanol and arabinose consumed, with large lag phases, and small $\mathrm{H}_{2}$ production potentials $(P)$.

\subsection{Partial Least Squares (PLS)}

In order to determine the relationship between parameters, a Partial Least Squares (PLS) regression was performed, individually, to each of the biomasses data sets with $P$ (hydrogen production potential) as the $Y$ variable, and lag-phase time, $R_{m}$ (maximum hydrogen production rate), arabinose consumed, volatile fatty acids, and ethanol as the $X$ variables.

When the PLS regression was performed no significant improvement in the prediction ability occurred for more than two latent variables in the $P$ study attaining a value for the multiple correlation coefficient (goodness of fit) of 97.8, 94.2, 98.9 , and $96.2 \%$, respectively for the S1, S2, G1, and G2 sludge data sets (Fig. 2).

The loading plots $w^{*} c$ display both the correlation between the $X$-weights $\left(w^{*}\right)$ and $Y$-weights $(c)$, and thereby the correlation structure between $X$ and $Y$. One sees how the $X$ and $Y$ variables combine in the projections, and how the $X$ variables relate to $Y$ and to each other. These weights are selected so as to maximize the covariance between $T$ and $U$, thereby indirectly $T$ and $Y$. It is important to note that variables with equivalent (positive or negative) weights are highly correlated. The variables with similar weights $\left(w^{*} c\right)$ are directly correlated, and variables are inversely proportional if their weights are symmetric, i.e. situated in opposite quadrants of the graph.

A high correlation $\left(R^{2}=0.973\right)$ was observed between the percentage of $n$-butyrate and the percentage of ethanol for G1 sludge (Fig. 3a). This suggested that the fermentation is following the butyrate/ethanol pathway corresponding to the lower yields of hydrogen obtained.
It is shown in Fig. 3b, that the percentage of $n$-butyrate is highly correlated with the percentage of acetate $\left(R^{2}=0.980\right)$ for the S1 sludge. This suggests that the system is following butyrate-acetate type fermentation with butyrate in excess.

\subsection{Acclimated granular sludge}

G2 sludge was obtained from hydrogen producing continuous system and the batch experiments revealed that this biomass achieved higher hydrogen production potentials and a higher percentage of arabinose consumption with a very large range of pHs (Table 1). This suggests that biomass acclimatization is very important to achieve higher hydrogen production values and higher percentages of substrate consumption. For a continuous system, high hydrogen production rates and small lag phases as well as tolerance to $\mathrm{pH}$ variations are essential. Suspended sludges showed higher yields of hydrogen production when compared to the granular sludges but were observed to have lower hydrogen production potentials and percentages of arabinose consumption and also longer lag phases. In general, granular sludges showed the highest hydrogen production potentials within a larger range of $\mathrm{pH}$ values that demonstrated a higher tolerance to $\mathrm{pH}$ changes. On the other hand, the maintenance of high biomass concentrations inside the reactors, such as those observed in granulebased systems, is necessary for a stable hydrogen production.

\section{Conclusions}

In the present study, all the sludges tested showed higher hydrogen production potential values with the utilization of higher initial $\mathrm{pH}$ values. Granular sludges obtained smaller lag phases and higher percentages of arabinose consumption. G2 (acclimatized granular sludge) showed highest hydrogen production potential values and percentage of arabinose consumption. Granular sludges (G1 and G2) showed different behaviour than the suspended sludges (S1 and S2). The differences were observed to be smaller lag phases, the percentage of acetate produced, the higher percentage of ethanol produced, and the amount of arabinose consumed. 
The percentage of $n$-butyrate is highly correlated with the percentage of acetate $\left(R^{2}=0.980\right)$ for S1 suggesting an acetatebutyrate main pathway. High correlation $\left(R^{2}=0.973\right)$ was also observed between the percentage of $n$-butyrate and the percentage of ethanol for G1. This suggested that the fermentation is following the butyrate/ethanol pathways which corresponded to the lower yields of hydrogen obtained. This study suggests that acclimatization of biomass is very important to achieve higher hydrogen production potentials and substrate consumption. Granular sludge can be used for larger $\mathrm{pH}$ ranges without losing its hydrogen production potential and arabinose uptake capacity when compared with suspended sludges.

\section{Acknowledgements}

We gratefully acknowledge the financial support awarded to A.A. Abreu (SFRH/BD/29823/2006), A.S. Danko (SFRH/BPD/ 24221/2005) and J.C. Costa (SFRH/BD/13317/2003) through individual grants and the project (POCTI/ENR/57786/2004) from Fundação para a Ciência e a Tecnologia (Portugal).

\section{R E F E R E N C E S}

[1] Nath K, Das D. Improvement of fermentative hydrogen production: various approaches. Appl Microbiol Biotechnol 2004;65:520-9.

[2] Das D, Veziroglu TN. Hydrogen production by biological processes: a survey of literature. Int J Hydrogen Energy 2001; 26:13-28.

[3] Levin DB, Pitt L, Love M. Biohydrogen production: prospects and limitations to practical application. Int J Hydrogen Energy 2004;29:173-85.

[4] Kondratieva EN, Gogotov I. Production of molecular hydrogen in microorganisms. Adv Biochem Eng 1983;28:139-91.

[5] Dabrock B, Bahl H, Gottschalk G. Parameters affecting solvent production by Clostridium pasteurianum. Appl Environ Microbiol 1992;58:1233-9.

[6] Van Ginkel S, Sung S, Lay JJ. Biohydrogen production as a function of $\mathrm{pH}$ and substrate concentration. Environ Sci Technol 2001;35:4726-30.

[7] Fang HP, Liu H. Effect of $\mathrm{pH}$ on hydrogen production from glucose by a mixed culture. Bioresour Technol 2002;83:87-93.

[8] Sung S, Raskin L, Duangmance T, Padmasiri S, Simmons JJ. Hydrogen production by anaerobic microbial communities exposed to repeated heat treatments. In: Proceedings of the 2002 U.S. DOE hydrogen program review; 2002 [NREL/CO:610-32405].

[9] Kim IS, Hwang MH, Jang NJ, Hyun SH, Lee ST. Effect of low pH on the activity of hydrogen utilizing methanogen in biohydrogen process. Int J Hydrogen Energy 2004;29:1133-40.

[10] Mulin C, Junxin L, Yuansong W. Enhanced biohydrogen production from sewage sludge with alkaline pretreatment. Environ Sci Technol 2004;38:3195-202.

[11] Khanal SK, Chen W-H, Li L, Sung S. Biological hydrogen production: effects of $\mathrm{pH}$ and intermediate products. Int $\mathrm{J}$ Hydrogen Energy 2004;29:1123-31.
[12] Kawagoshi Y, Hino N, Fujimoto A, Nakao M, Fjita Y, Sugimura S, et al. Effect of inoculum conditioning on hydrogen fermentation and $\mathrm{pH}$ effect on bacterial community relevant to hydrogen production. J Biosci Bioeng 2005;100(5):524-30.

[13] Jianzheng L, Nanqui R, Baikun L, Zhi Q, Junguo H. Anaerobic biohydrogen production from monosaccharides by a mixed microbial community culture. Bioresour Technol 2008;99: 6528-37.

[14] Danko AS, Abreu AA, Alves MM. Effect of arabinose concentration on dark fermentation hydrogen production using different mixed cultures. Int J Hydrogen Energy 2008; 33:4527-33

[15] Taguchi F, Mizukami N, Hasegawa K, Saito-Taki T. Microbial conversation of arabinose and xylose to hydrogen by newly isolated Clostridium sp. No. 2. Can J Microbiol 1994; 40:228-33.

[16] Abreu AA, Danko AS, Alves MM. Biohydrogen production with an EGSB reactor using chloroform and 2-bromoethanesulfonate as hydrogen-consuming bacteria inhibitors. In: Proceedings of the 10th international chemical and biological engineering conference (CHEMPOR), Braga, Portugal; 2008.

[17] Colleran E, Concannon F, Goldem T, Geoghegan F, Crumlish B, Killilea E, et al. Use of methanogenic activity tests to characterize anaerobic sludges, screen for anaerobic biodegradability and determine toxicity thresholds against individual anaerobic trophic groups and species. Water Sci Technol 1992;25:31-40.

[18] Zehnder AJB, Huser BA, Brock TD, Wuhrmann K. Characterization of an acetate-decarboxylating, nonhydrogen-oxidizing methane bacterium. Arch Microbiol 1980;124:1-11.

[19] Owen WF, Stuckey DC, Healy Jr JB, Young LY, MacCarty PL. Bioassay for monitoring biochemical methane potential and anaerobic toxicity. Water Res 1979;13:485-92.

[20] APHA, AWWA, WPC. Standard methods for the examination of water and wastewater. 17th ed. Washington, DC: American Public Health Association; 1989.

[21] Lay JJ, Lee YJ, Noike T. Feasibility of biological hydrogen production from organic fraction of municipal solid waste. Water Res 1999;33:2579-86.

[22] Zwietering MH, Jongenburger L, Rombouts FM, van't Riet K. Modelling the bacterial growth curve. Appl Environ Microbiol 1990;56:1875-81.

[23] Einax JW, Zwanziger HW, Geiss S. Chemometrics in environmental analysis. Weinheim: VCH; 1997.

[24] Lin CY, Cheng CH. Fermentative hydrogen production from xylose using anaerobic mixed microflora. Int J Hydrogen Energy 2006;31(7):832-40.

[25] Moat AG. Microbial physiology. New York: John Wiley \& Sons; 1979. p. 123-89.

[26] Thauer RK, Jungermann K, Decker K. Energy conversion in chemotrophic anaerobic bacteria. Bacteriol Rev 1977;41(1): 100-80.

[27] Fang HHP, Lui H. Granulation of a hydrogen-producing acidogenic sludge. In: Proceedings part 2 of the 9th world congress on anaerobic digestion, vol. 2; 2001. p. 527-32.

[28] Noike T, Mizuno O. Hydrogen fermentation of organic municipal wastes. Water Sci Technol 2000;24(8):17-23.

[29] Massart DL, Heyden YV. From tables to visuals: principal component analysis, part 2. Practical data handling. LC/GC Europe 2005;18(2):84-9. 